\title{
Rethinking Survivorship: Communication is the Key
}

Gladys Rodriguez, MD, Niharika Dixit, MD

University of California San Francisco, San Francisco, CA; University of California San Francisco/ZSFG San Francisco, CA

\section{Background}

Primary care providers (PCPs) play a critical role in the comprehensive care of cancer survivors.

Safety net providers often need to provide cancer survivorship care in limited resource settings.

$\square$ Prior research has found that PCPs in safety net networks lack the knowledge and confidence in survivorship care for breast cancer survivors.

$\square$ Coordination between specialists and PCPs is a vital component of cancer survivorship care to ensure that all of the survivor's needs are met.

$\square$ Most cancer survivors have additional comorbidities and would benefit from better communication and coordination between specialists and primary care providers.

\section{Objectives}

Assess knowledge and attitudes of PCPs regarding care of breast and colon cancer survivors in a safety net health network.

2. Assess communication between PCPs, oncologists and patients.

\section{Methods}

$\square$ A modified National Cancer Institute and American Cancer Society Survey of Physician Attitudes Regarding the Care of Cancer Survivors (SPARCCS) was sent electronically to 220 PCPs in 12 primary care clinics.

$\square$ Primary care clinics are part of the San Francisco Health Network affiliated with Zuckerberg San Francisco General Hospital and Trauma Center.

$\mathrm{N}=110$, response rate $=50 \%$

$\square$ Descriptive statistical analysis was conducted with SAS software.

$\square$ PCPs quotes were obtained from comments section on survey.

\section{Four components of cancer} survivorship:

1. Surveillance for recurrence of new primaries.

2. Identification and management of long term and late effects from cancer and its therapies.

3. Health care maintenance

4. Coordination between specialists and PCPs to ensure that all of the survivor's needs are met.

Table 1: PCP Characteristics

\begin{tabular}{|c|c|c|}
\hline Characteristics & $\overline{\%(n)}$ & \multirow{3}{*}{$\begin{array}{l}\text { Receive a comprehensive summary } \\
\text { including cancer treatment informatio } \\
\text { from the patient's oncology specialist }\end{array}$} \\
\hline Specialt & & \\
\hline Internal & $36.0 \%(29)$ & \\
\hline Medicine & & \multirow{3}{*}{$\begin{array}{l}\text { Provide a summary of the patient's } \\
\text { past non-cancer medical history for th } \\
\text { patient's oncology specialist. }\end{array}$} \\
\hline $\begin{array}{l}\text { Family } \\
\text { Medicine }\end{array}$ & $60.0 \%(49)$ & \\
\hline Other & $4.0 \% \quad(3)$ & \\
\hline Training & & \multirow{3}{*}{$\begin{array}{l}\text { Receive information from the oncolog } \\
\text { specialist in a timely manner. } \\
\text { Experience difficulties transferring } \\
\text { patient care responsibilities between } \\
\text { you and the oncology specialist. }\end{array}$} \\
\hline MD/DO & $64.0 \%(52)$ & \\
\hline $\begin{array}{l}\text { Advanced } \\
\text { Practitioner NP/ } \\
\text { PA }\end{array}$ & 23.0 & \\
\hline $\begin{array}{l}\text { Resident/ } \\
\text { Fellow }\end{array}$ & $12.0^{\circ}$ & \multirow{4}{*}{$\begin{array}{l}\text { Receive from oncologist an explicit } \\
\text { follow-up care plan documenting } \\
\text { recommendations for future care and } \\
\text { surveillance. }\end{array}$} \\
\hline Race & & \\
\hline White & $62.0 \%(51)$ & \\
\hline Asian & $27.0 \%(22)$ & \\
\hline
\end{tabular}

\section{Black or African 7.5\% (6) PCPs and patients}

American

American

$2.5 \%(2)$

Indian/Alaska

Native

Ethnicity

Hispanic

Non-Hispanic

Primary site of practice

Hospital based primary care

Community

based primary

care

Non-SF health network site

Number of

patients seen

weekly

25 or fewer

26-50

50 or greater

Patients with

limited English

proficiency

\section{$1-25 \%$ \\ $25-50 \%$ \\ $50-75 \%$ \\ $75-100 \%$ \\ Teaching \\ $16.0 \%(13)$ \\ $46.0 \%(37)$ \\ $22.0 \%(18)$ \\ $14.0 \%(11)$ \\ Figure 2: PCPs' Comments on Communication with Oncology Specialists}

Position

Yes

No

Training in

Survivorship

Care

Yes/Somewhat 33.3\% (27)

No $\quad 66.7 \%(54)$

Patients with

Medicaid

(MediCal)

\begin{tabular}{ll}
$<50 \%$ & $25.0 \%(20)$ \\
$>50 \%$ & $65.5 \%(84)$ \\
\hline
\end{tabular}

$67.9 \%(55)$

$32.1 \%(26)$

Have a specific discussion with the patient regarding recommendation for future care and surveillance.

Discuss with the patient who will provide follow up care for cancer.

$6.0 \%$ (5) Discuss with your patient who will $94.0 \%$ (76) provide care for other medical issues.

\section{PCPs and other providers}

Communicate with patients' other

physicians about responsibility of follow up care for their cancer.

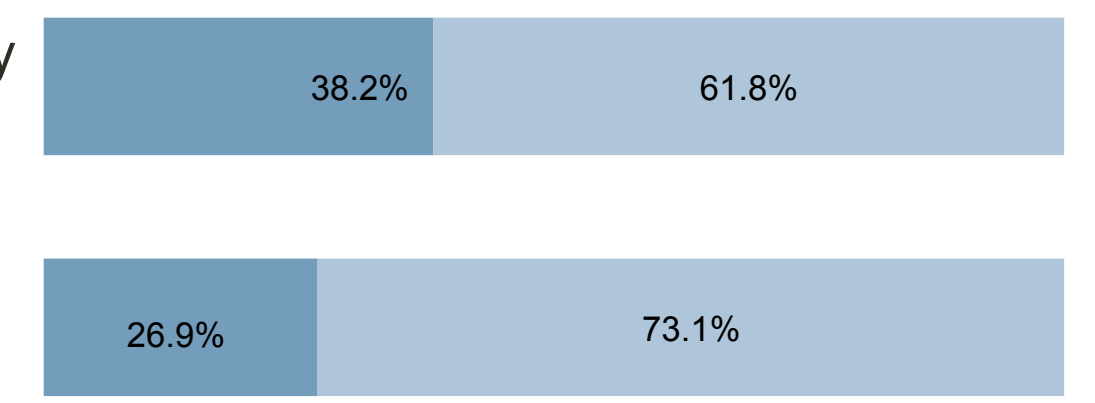

Communicate with patients' other physicians about responsibility for follow up of other medical issues.

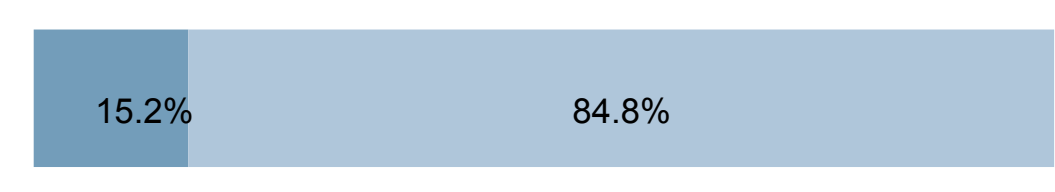

Table 2: Barriers to Providing Survivorship Care

\begin{tabular}{|l|c|}
\multicolumn{1}{|c|}{ Barriers to Providing Care } & Never/Rarely \\
\hline $\begin{array}{l}\text { I am uncertain about which physician is providing general } \\
\text { preventive care }\end{array}$ & $58.0 \%$ \\
\hline Concern of duplication of effort between oncologists \& PCPs & $47.4 \%$ \\
\hline Concerns about missed care due to unclear delineation of roles & $30.8 \%$ \\
\hline $\begin{array}{l}\text { Patients contact me for problems that should be treated by } \\
\text { oncology specialist }\end{array}$ & $47.0 \%$ \\
\hline
\end{tabular}

I don't have adequate knowledge to provide care for my patients

$25.0 \%$

"The oncology notes do not make the surveillance plan clear. -There isn't a specific 'hand off' plan and communication."

"Improved communication around what the follow up plan should be for a particular cancer survivor would be much appreciated."

"Bidirectional communication between the oncologist and primary care provider is highly desirable, but often lacking."

"There is NO communication from oncology to PCPs at all, including about what the long term agreements/ plan/treatment should be."

\section{Conclusions}

- Primary care providers in the San Francisco Health Network reported suboptimal communication between the oncologists and PCPs and between PCPs and patients.

- Poor delineation of care was a key factor for concern for missed care of cancer survivors.

Improving communication can significantly optimize cancer survivors' care. 